\title{
Review of the Recent Development of Electrical \\ Sheet Steel in Japan*
}

\author{
By Satoru TAGUCHI**
}

\begin{abstract}
Synopsis
Progress during last decade has been remarkable. Non-oriented electrical steels with excellent semi-organic coatings were developed. This helped to improve the productivity greatly by improving the workability. Among the grain-oriented electrical steels, the development of ones with high permeability is noted. With these steels the remarkably reduced hysteresis loss attained by a high degree of grain orientation alignment and the reduction of the eddy current loss by means of tensile stress induced by surface coating are the essential features. Transformers made from these steels have demonstrated their superiority over conventional counterparts in their lower total loss, lower exciting power and lower noise.
\end{abstract}

\section{Preface}

The electrical steel was first produced in Europe and in the United States. Since the manufacturing techniques in Japan were then very retarded, they had to be introduced from the United States around 1952. Also the related techniques for equipments, etc., became rapidly developed at about the same time. As a result, independent development of similar products in Japan became possible, and production and quality gradually increased. The progress during the last decade has been remarkable. Even though elsewhere, the electrical steel had reached the stage of stability and showed few significant changes in quality, in Japan, grain-oriented electrical steels with high permeability were developed ahead of the rest of the world and non-oriented electrical steels with excellent surface insulation coating were developed. Some of these advances will be discussed below.

\section{Progress of Electrical Steel}

It was in about 1900 that the addition of silicon was started. In Germany, industrial production of the steel commenced in 1903.

In 1903, Hadfield's patent ${ }^{1)}$ was issued, and a right to use this patent was acquired by a firm in the United States to commence industrial production of electrical steel. By about 1906, steels containing up to $3 \% \mathrm{Si}$ were made. Technically, the quality was improved by raising the $\mathrm{Si}$ content, lowering the carbon content, and elevating the annealing temperature as well as through the advancement of steelmaking technology. While all the electrical steels were made by hot rolling, those for rotating machinery were gradually replaced with cold-rolled hoop, and it became possible to punch out core material by a continuous punching machine. Hot-rolled electrical steels of high silicon contents up to about $5 \%$ Si were developed for transformers. These products or sheets, coated with an annealing separator compound and stacked, were annealed for a long time at above $1100^{\circ} \mathrm{C}$ in a nitrogen atmosphere to reduce the total loss.

Innovation in the development of electrical steel is the grain-oriented electrical steel. In 1934, Goss obtained a patent ${ }^{2)}$ on the method of manufacture. It was a two-stage cold reduction process with an intermediate annealing, and was developed chiefly by Armco Steel Corporation of the United States. In the original Goss method, the products came up with a high total loss because the finish annealing was continuous, so the high-temperature long-time box annealing was adopted.

As it was necessary to carry out decarburization during the process, a method ${ }^{3)}$ of strip annealing in wet hydrogen for decarburization was developed. While it is necessary, in annealing the steel in a coil form, to coat with an annealing separator, the technique $^{4)}$ of coating with $\mathrm{MgO}$ powder and having a glass film formed through reaction with the oxide layer produced on decarburizing anneal during box annealing was developed. In addition, the high temperature slab reheating ${ }^{5}$ for hot rolling, which is an important feature of this manufacturing method, helped to improve the orientation property and stabilize the product characteristics.

The development of these various techniques led to advancement of grain-oriented electrical steels and brought the steel into increasing use mainly for transformers.

Thereupon, the Armco Steel Corporation began to offer foreign countries licenses on hot-rolled electrical steel from about 1950, followed by licenses on grainoriented electrical steel. This led to about $80 \%$ of the world's grain-oriented electrical steel being manufactured in accordance with Armco techniques, the remaining $20 \%$ by similar but different manufacturing methods.

Although grain-oriented electrical steels made a remarkable progress, from about 1960 on no significant changes were made as if prevailed by a stabilized situation; these seems to have been a general agreement that the steel, technically, came to the stage it should reach.

What changed this situation was the grain-oriented electrical steel with high permeability ${ }^{6-8)}$ which came into being from Nippon Steel Corporation under the name "ORIENTCORE HI-B". Industrialization tests were started in 1964, and official sales in 1968. Licenses were furnished to Armco Steel Corporation

* Originally published in Tetsu-to-Hagané, 62 (1976), 905, in Japanese. English version received October 12, 1976

** Process Technology R \& D Laboratories, Nippon Steel Corp., Edamitsu, Yahatahigashi-ku, Kitakyushu 805. 
in 1971, to ATH in 1972, to Chatillon of France and Cockerill of Belgium in 1974, and to BSC in 1975. In 1973 Kawasaki Steel Corporation announced RGH, ${ }^{9}$ a grain-oriented electrical steel with high permeability, and started sales in 1974. In the same year, a license was offered to Surahammers of Sweden.

Figure 1 shows the changes in electrical steel production in Japan. It is seen that production increased with the increase in generation of electricity. Figure 2 shows changes in production in major industrialized countries. There has been a remarkable growth in Japan during the last 10 years. In the case of the United States, total production is not very great because commercial quality low carbon steel sheets are

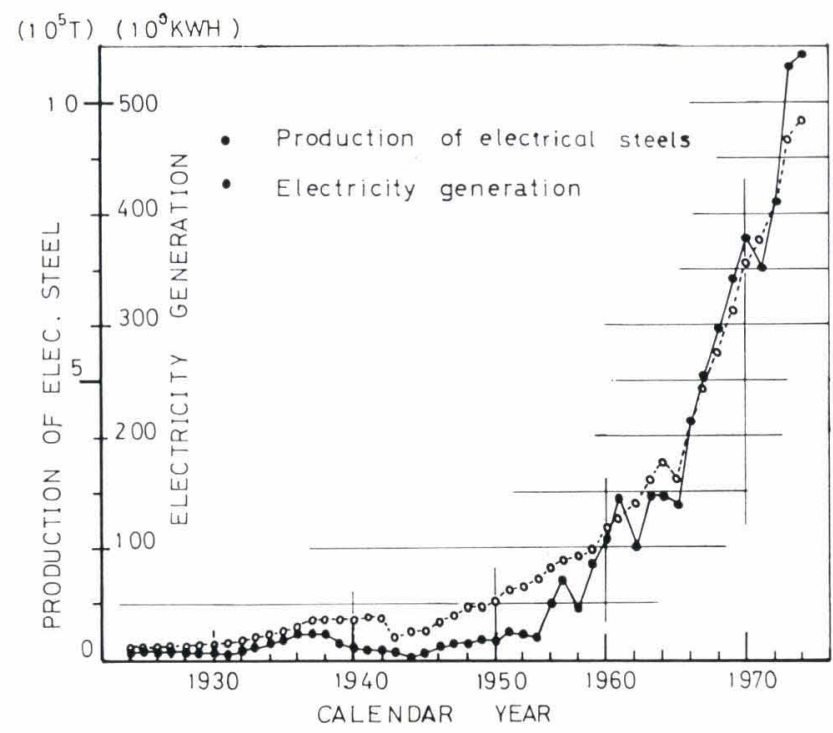

Fig. 1. Production of electrical steels and electrical power generated in Japan

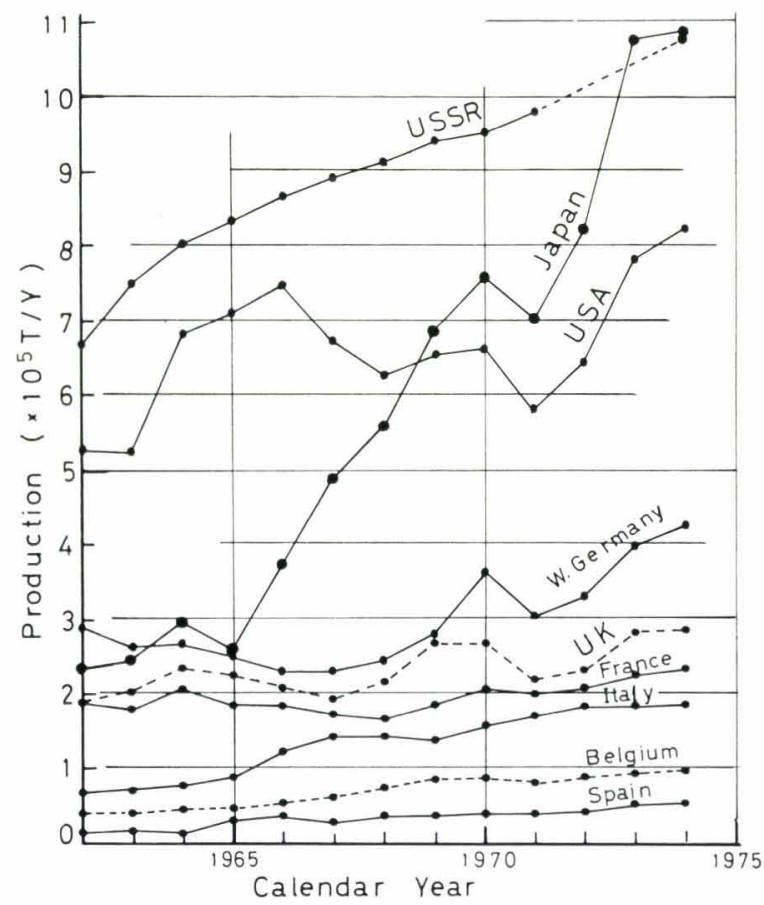

Fig. 2. Electrical steel production in various countries used in large quantities for small motors and because the use of lower grades corresponding to S30 to S60 such as employed in Japan is therefore extremely limited.

The recent progress of electrical steel is marked by the advent of the grain-oriented electrical steel with high permeability, but there are no new developments in the category of non-oriented electrical steel, the main stress being laid on the lower-grade products for small motors and on the development of surface coatings.

\section{Non-oriented Electrical Steel}

Generally, there are the medium and the high grades of electrical steel with more than $0.5 \% \mathrm{Si}$ and the low grades with less than $0.5 \% \mathrm{Si}$. Besides, siliconfree inexpensive magnetic steels are being made for small motors for household electrical appliances and in other applications. Also in production are some grades almost identical to low carbon steel sheets, which, after being punched, are annealed by the customers before use. Even though they are used in great quantities in the United States, in Japan, the use of low carbon steel sheets is extremely limited. By customer applications, they are classified into fully processed products and semi-processed products, the latter being annealed by the customers after fabrication to improve magnetic properties.

In the higher grades of products in which the total loss is required to be low, the content of $\mathrm{Si}$ is higher and therefore the magnetic flux density lower, but the lower grades are marked by a high magnetic flux density as they contain little or no silicon. Generally, the low grades are used with a thickness of $0.5 \mathrm{~mm}$, but in some cases they are used with greater thicknesses for reduction of fabrication expenses.

The medium grades are also of rather heavy gauge in most instances, but some come in a thickness of $0.35 \mathrm{~mm}$. The high grades in which the total loss is required to be low are manufactured in thicknesses of 0.35 and $0.5 \mathrm{~mm}$.

\section{Progress of Non-oriented Electrical Steel}

In Japan, cold-rolled non-oriented electrical steel started with the production of medium grades corresponding to JIS S23 or S18, and the low and high grade products came into production, as shown in Fig. 3. In the field of small motors, etc., where high magnetic flux density and low cost are preferable to low total loss, the grades lower than S30 which have low Si contents came into being. For large rotating machinery or small transformers, furthermore, in which low total loss is required, the grades of S12 and $\mathrm{S} 14$ are produced. Moreover, the high grades $\mathrm{H} 10$ and H9, though not provided for in JIS, are being manufactured.

The higher grades are higher in $\mathrm{Si}$ content and in resistivity, and ensure a lower total loss, but have the shortcoming that saturated magnetic flux density is lower.

Figure 4 shows the relation of typical total loss 


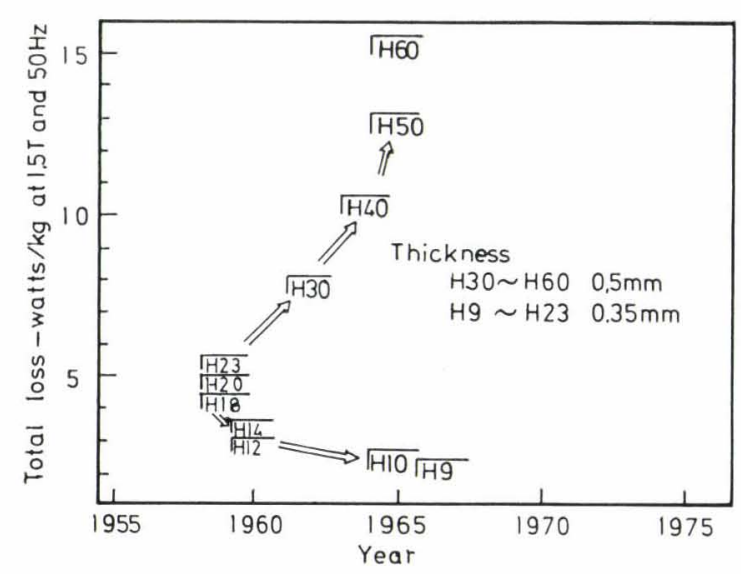

Fig. 3. Status of commercial grades of non-oriented electrical steels in Japan

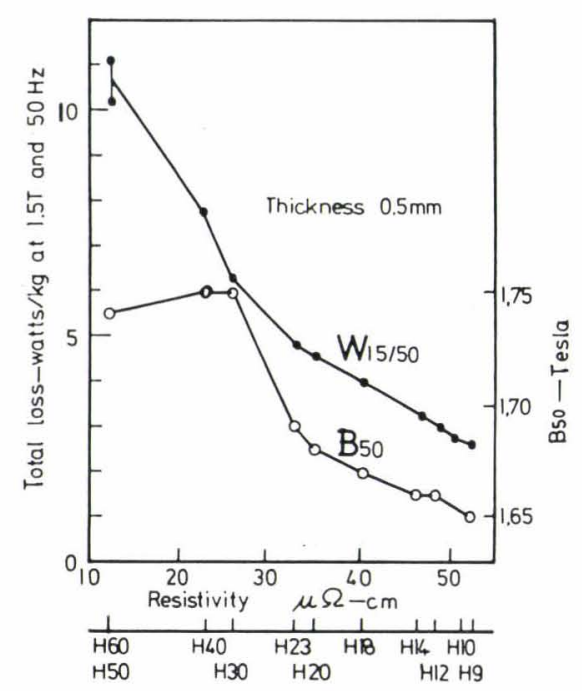

Fig. 4. Typical electrical and magnetic properties of commercial grades of non-oriented electrical steels

$\mathrm{W}_{15 / 50}$ (at 1.5 Tesla and $50 \mathrm{~Hz}$ ) and magnetic flux density $B_{50}$ (at $5000 \mathrm{~A} / \mathrm{m}$ ) versus typical resistivity in various classes of fully processed products ranging from H60 (equivalent to S60, JIS) to H9. The low grades are suitable for small motors in which magnetic flux density is of importance, and the high grades are used for large rotating machinery in which total loss is of importance. The low, medium and high grades of non-oriented electrical steel are all necessary according to their respective properties and applications.

For the semi-processed products, the guaranteed values generally adopted are their magnetic properties as obtained after customer annealing at $750^{\circ} \mathrm{C}$ for $2 \mathrm{hr}$. In Japan, $0.5 \mathrm{~mm}$ thick products of HS30, a standard equivalent to S30, are mainly in use.

Besides, electrical steels adaptable to various specific applications have been developed. For example, for equipments working at high frequencies, light-gauge non-oriented electrical steels of 0.15 and $0.20 \mathrm{~mm}$ in thickness are produced. For high-speed rotating machinery, which calls for high mechanical strength, high-strength non-oriented electrical steels with a tensile strength in the order of $60 \mathrm{~kg} / \mathrm{mm}^{2}$ are in production. In addition, wear-resistant non-oriented

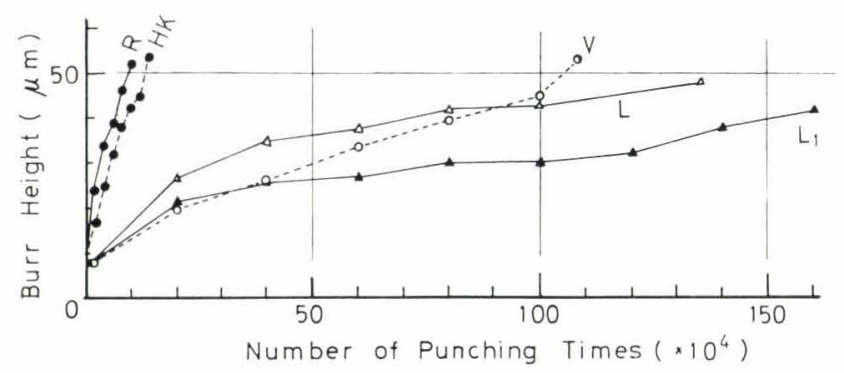

Material: H40, $0.5 \mathrm{~mm}$ thick

$\mathrm{R}, \mathrm{HK}$ : Inorganic coating

$\mathrm{L}, \mathrm{L}_{1}$ : Semi-organic coating

$\mathrm{V} \quad$ : Organic coating

Tool steel die, $5 \mathrm{~mm}$ dia., 340 stroke $/ \mathrm{min}$, clearance $5 \%$

Fig. 5. Effect of coating on punchability

electrical steels are being manufactured for magnet switches.

\section{Improvement of Workability}

Recent advances were concerned with the low grades of electrical steels for small motors and with the development of insulation coatings. It was desired that these grades should have high magnetic flux density even though the total loss might increase somewhat, excel in workability, and be inexpensive.

Insulation coatings are primarily for insulation between the layers of a laminated core, but in the small motor application, very slight insulation resistance is sufficient. Therefore, improvement was sought in other properties of the coating such as punchability, weldability, prevention of sticking in annealing and corrosion resistance. Formerly, inorganic coatings of phosphate, chromate, etc., were utilized for insulation, but the development of resins, particularly watersoluble or emersion resins, led to the development of semi-organic coating which have both good workability and heat resistance as formed by combining those resins with inorganic salts, particularly chromate. These coatings, compared with conventional inorganic coatings, have an excellent punchability, a sufficient heat resistance which is characteristic of inorganic material and a sufficient resistance to refrigerants such as freon. Coatings of this type are being utilized for almost all the low grade electrical steels.

Punchability, while being dependent both on the mechanical properties of the steel and on the nature of the surface oxide layer, is greatly affected by the coating, as shown in Fig. 5. When a punching test is conducted with a circular punch of $5 \mathrm{~mm}$ in diameter, the number of punchings until the burrs reach $50 \mu \mathrm{m}$ varies from 100000 to about 3 million depending on the type of coating. In the actual punching of cores, a big difference like this does not occur due to the complexity of core shape, yet punchability has made great progress through the improvement of coatings. In Japan, the stators of small motors usually have their periphery fastened by welding, and workability has become greatly improved through improved weldability, machinability of rotor, etc. 


\section{Grain-oriented Electrical Steel}

Figure 6 shows how the total loss, represented here by $W_{15 / 50}$, i.e., values at 1.5 Tesla and $50 \mathrm{~Hz}$, has improved. It will be seen that, with the advent of grainoriented electrical steel, the total loss decreased markedly, and that this steel continued to gain ground until about 1960, but with little change seen thereafter. This situation is shown in Fig. 7 in terms of the changes in the $W_{17 / 50}$, the total loss value at 1.7 Tesla and $50 \mathrm{~Hz}$, of Japanese commercial grainoriented electrical steels. With regard to HI-B, a new grain-oriented electrical steel with high permeability that brought about a remarkable change, more will be told later on.

Most of the grain-oriented electrical steel is used for transformer cores with the exception of a very small percentage employed for generators. The use of an electrical steel having lower total loss results so directly in transformers having lower total loss that demands of ever up-grading the core electrical steel are inevitable. The grain-oriented electrical steel is a product which is destined to develop towards ever higher grades; once a higher grade is put on sale, the production of other grades will taper off since they have no reason for continuing existence except for their inexpensiveness.

The drastic progress brought about by the grainoriented steel has been achieved through reducing the hysteresis loss on the following principle. Iron is magnetized differently in different crystallographic directions: the [001] axis is the direction in which magnetization is the easiest, the [111] is the direction in which magnetization is most difficult, and the [011] is intermediate. It has been discovered that by manipulating the rolling process in certain way, it is possible to have the (110) [001] texture developed in silicon steels.

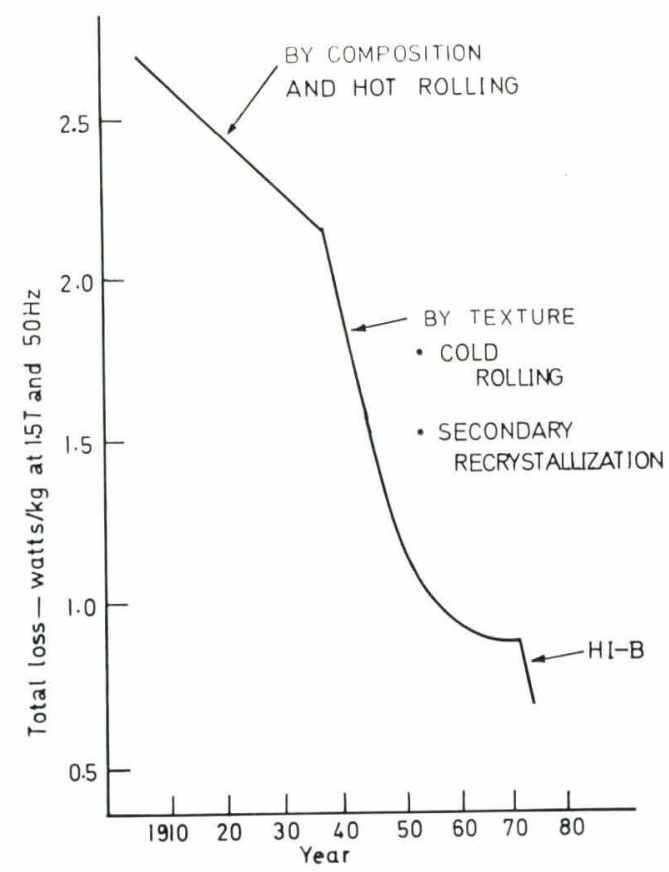

Fig. 6. Lowest total loss attained by commercial electrical steels in each year
Namely, the grain-oriented electrical steel is an aggregate of grains of (110) [001] orientation having the [001] axis parallel to the rolling direction and the (110) face parallel to the rolling plane. It will be appreciated that the greater the degree of grain orientation alignment, i.e., having the more grains assume an orientation close to the ideal (110) [001], the better the quality.

Here, it will be remembered that the total loss may be broken down mainly into hysteresis loss and eddycurrent loss, and that they are affected by the following factors :

$$
\begin{gathered}
\text { Hysteresis loss }\left\{\begin{array}{l}
\text { Grain orientation } \\
\text { Purity (inclusions, precipitates) } \\
\text { Internal stress }
\end{array}\right. \\
\text { Eddy-current loss }\left\{\begin{array}{c}
\text { Electrical resistivity (silicon } \\
\text { content) } \\
\text { Tensionalstress (surface coating) } \\
\text { Size of magnetic domain (grain } \\
\text { size) }
\end{array}\right.
\end{gathered}
$$

In the conventional products, improvement of hysteresis loss was sought by decreasing inclusions and internal stress, etc., and improvement in the eddy-current loss was sought by raising the Si content to increase electrical resistivity, by decreasing the steel thickness, by refining the grain size, etc. As a result, a great quality improvements were realized, but it was considered, as mentioned earlier, that a ceiling was closely approached because $3.25 \%$ was the limit of $\mathrm{Si}$ content and there appeared no room for further improvement of steel cleanliness, reduction of internal stress, reduction of steel thickness, etc. In addition to these two kinds of energy loss, there are other requirements to be taken into consideration. For example, the electrical steel must be uniform in thickness and flat since it is used in laminated form. Recently, moreover, the noise of transformers has become an important problem, and it is necessary that the magnetostriction of electrical steel, one of the noize factors, be held small.

In the new grain-oriented electrical steel with high permeability, as we shall see, the innovative improvement of the grain orientation alignment markedly de-

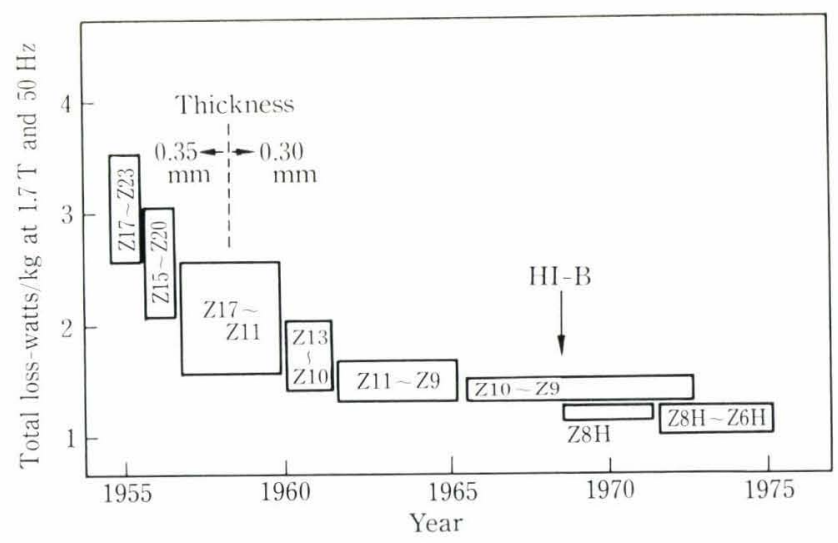

Fig. 7. Improvements in total loss of commercial grades of grain-oriented electrical steels in Japan 
creased the hysteresis loss, while the tension effect of surface coatings decreased the eddy-current loss and the magnetostriction.

Grain-oriented electrical steels are being produced in thicknesses of $0.35,0.30$ and $0.27 \mathrm{~mm}$. The decrease in the steel thickness decreases the eddy-current loss and the total loss, but increases the number of man-hours in the fabrication and assembly of transformer cores. In the United States and in Europe, $0.27 \mathrm{~mm}$ products are used for wound cores and for laminated cores which involve critical total loss requirements, and $0.30 \mathrm{~mm}$ products are used for laminated cores. In Japan, $0.30 \mathrm{~mm}$ products are commonly employed for wound cores, and $0.35 \mathrm{~mm}$ products for laminated cores.

\section{Manufacturing Features}

Table 1 shows the manufacturing processes of grainoriented electrical steels. In the past, the grain-oriented electrical steel was manufactured by the twostage cold reduction method in various countries, in which $\mathrm{MnS}$ is employed as the inhibitor. Namely, manganese and sulfur are added in the steelmaking process, then slabbing and hot rolling are conducted, after which final steel thickness is obtained through cold reduction performed in two stages with an intermediate annealing. After decarburizing anneal final annealing is carried out to have large grains grow. In this case, during hot rolling, the slab is heated to a high temperature to bring $\mathrm{MnS}$ in solution, and after hot rolling, $\mathrm{MnS}$ is reprecipitated dispersing finely as the steel is cooled. Then, in the final or box annealing, the larger of (110) [001] grains grow at the expenses of the primary recrystallized grains which are kept from growing very much by the $\mathrm{MnS}$ precipitates. As the annealing is prolonged, $\mathrm{MnS}$ precipitates become coagulated, and loosing the inhibition effect, let the secondary recrystallization take place rapidly in which to form the desired texture. The $\mathrm{MnS}$, in the mean time, is absorbed in the glass film formed on the surface and made harmless to magnetic properties. In general practice, continuous annealing is additionally conducted to obtain a flat surface and apply inorganic insulation coating.

As shown in the (100) pole figure of Fig. 8 (b), the deviation of the [001] axis from rolling direction is within $10^{\circ}$ in $75 \%$ of the cases examined with the average of about $7^{\circ}$. The degree of orientation alignment is well represented by magnetic flux density at $800 \mathrm{~A} / \mathrm{m}$ (approx. $10 \mathrm{Oe}$ ), which is higher with products having better orientation alignment. In the conventional two-stage cold reduction method, the $B_{8}$ is about 1.82 Tesla, and despite the efforts made to improve the degree of orientation, $B_{8}$ appeared to have hit its upper limit at 1.83 Tesla, beyond which any further improvement of orientation was considered industrially impossible.

For this reason, reduction of the total loss was attempted by decreasing the sheet thickness. In the United States, the manufacture of $0.23 \mathrm{~mm}$ products was attempted for some time, but was eventually given up since its industrialization was costly and the desired low total loss was difficult to attain. In the two-stage cold reduction method, $0.27 \mathrm{~mm}$ products have shown the best properties currently attainable. This twostage cold reduction method is held to be an almost perfected technology as it leaves little room for improvement even if the manufacturing conditions are modified in the future. Some of the guaranteed total loss for electrical steel are shown in Table 1 .

In contrast, HI-B, the grain-oriented electrical steel with high permeability, is manufactured by a onestage cold reduction method employing AIN as an inhibitor. Namely, as shown in Table 1, aluminum and nitrogen are added in the steelmaking process, and slabbing and hot rolling are performed, after which the steel is subjected to AIN precipitation annealing. Next, it is brought to final thickness by one-stage heavy cold reduction, following which it is decarburized and box annealed. Now, this was quite contrary to the

Table 1. Manufacturing process and guarantéed maximum total loss

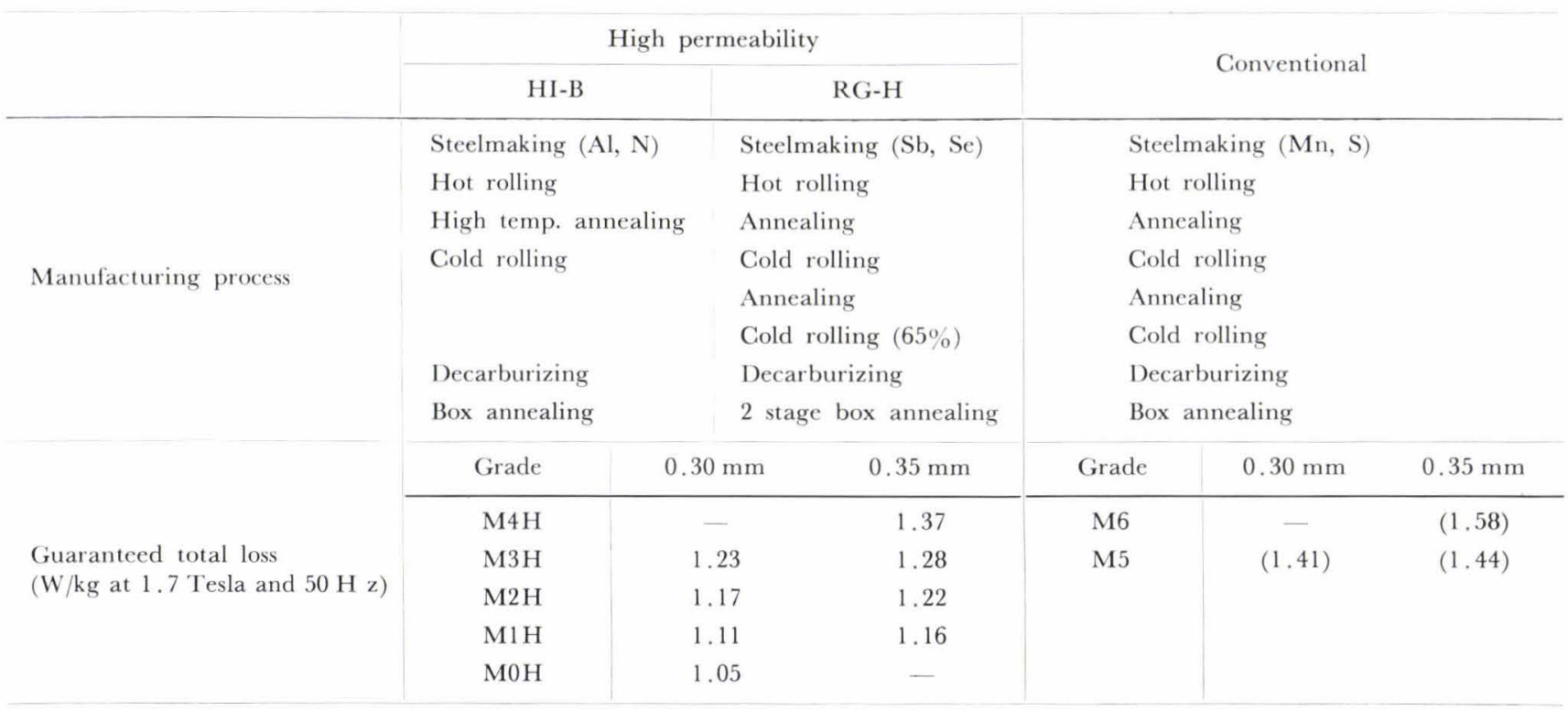




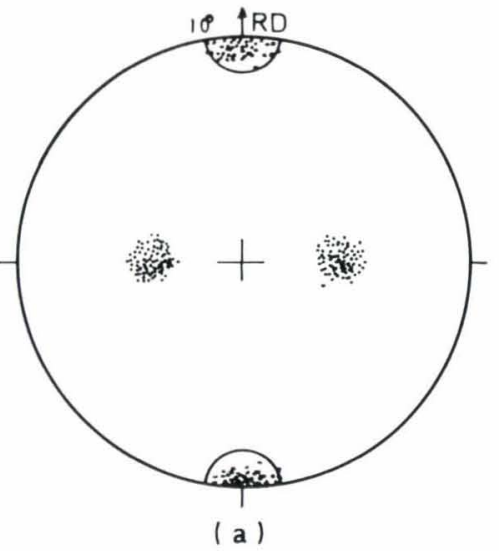

(a)

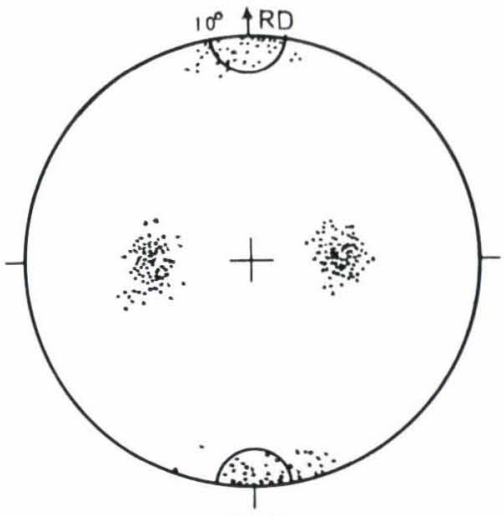

(b) (a) an ORIENTCORE HI-B

(b) a conventional grain-oriented steel.

Any one grain is represented by a set of 4 dots, one each in the four concentrations.

Fig. 8 . The (100) pole figures showing the orientation alignment of grainoriented electrical steel generally accepted theories. Namely, for conventional grades of grain-oriented electrical steel, manufacture by the one-stage cold reduction method was held impracticable and AIN harmful. The fact is, however, the excellent features ${ }^{10-12)}$ of AIN may well be combined with one-stage cold reduction to give rise to a greatly improved orientation alignment. Namely, not only AIN gets dissolved and diffused at temperatures above $1100^{\circ} \mathrm{C}$ to be absorbed into the glass film, but in this product, the deviation of the [001] axis from the rolling direction is very small, being within $10^{\circ}$ in all the cases examined and averaging $3^{\circ}$. The $B_{8}$ stands at 1.92 Tesla, a drastic improvement over the 1.82 Tesla of conventional products. Further, the glass film formed at a high temperature, being a sort of ceramic material, has a very small coefficient of thermal expansion. Therefore, a tensile stress is produced at the surface from the difference between the thermal expansion coefficients of the surface coating and the steel. The inorganic coating which is applied on the sheet can also give a similar effect. The effect of this tension on magnetic properties is slight when $B_{8}$, or the orientation alignment, remains to be about 1.82 Tesla, but becomes greater when $B_{8}$ reaches 1.9 Tesla or so to decrease the total loss through a combined action with improved orientation.

The RG-H, a grain-oriented electrical steel with high permeability, on the other hand, is manufactured by the two-stage cold reduction method but with the addition of antimony and selenium in the steelmaking process, ${ }^{13)}$ as shown in Table 1. With Sb and MnSe used as inhibitors, the steel is subjected to a second cold reduction at a high rates of 60 to $70 \%$ and held between $820^{\circ}$ and $900^{\circ} \mathrm{C}$ for a long time in final box annealing to have the secondary recrystallization to take place, after which it is subjected to high-temperature annealing. The guaranteed total losses of those grain-oriented electrical steels are given in Table 1 .

\section{Magnetic Properties}

Figure 9 is a typical example of the separation of total loss into components, showing the relation between total loss per cycle at 1.7 Tesla and frequency. As the hysteresis loss is proportional to frequency the hysteresis loss per cycle is considered constant. Of

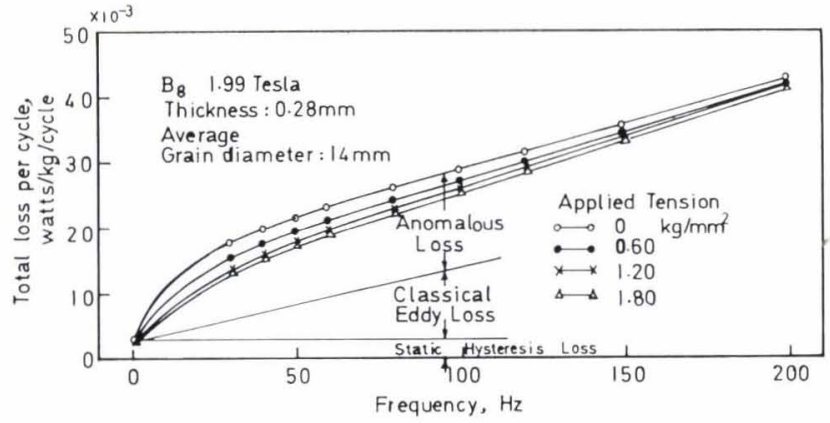

Fig. 9. Effect of applied tension on total loss per cycle against frequency for a grain-oriented $3 \% \mathrm{Si}$ steel. Measurement of total loss were made at 1.7 Tesla for samples with chemically polished surfaces.

the three components of the total loss, the classical eddy-current loss is that portion of the eddy-current loss when magnetization varies uniformly in the material. It is proportional to the square of sheet thickness, frequency, and maximum magnetic flux density, respectively, and inversely proportional to resistivity. Per cycle, therefore, it is proportional to frequency. The anomalous eddy-current loss, the eddy-current loss arising from movement of the domain wall, on the other hand, is proportional to the square of the velocity of movement of the domain wall, which is proportional to the frequency of magnetization. Therefore, the anomalous eddy-current loss per cycle should again be proportional to frequency. At low frequencies, say, below $30 \mathrm{~Hz}$, however, this proportionality is lost for a number of reasons, one of which is the phenomenon that the number of magnetic domains varies with frequency. For the same frequency, further, the velocity is proportional to the distance of movement of the domain wall, so the velocity and the eddycurrent loss increase with increasing width of domain. If the width of domain increases, however, the number of domain walls decreases, so the anomalous eddycurrent loss is nearly proportional to the width of domain instead of the square of width of domain.

The proportion of anomalous eddy-current loss has increased with the progress of grain-oriented electrical steel, and today it is as much as about $50 \%$ of the total loss at the commercial frequencies, 50 and $60 \mathrm{~Hz}$. To decrease this, it is important to reduce the domain 
width. For this, it is important to increase the tension effect which attends on the improvement of orientation, that is, the improvement of $B_{8}$.

\section{Orientation and Hysteresis Loss}

The hysteresis loss decreases markedly ${ }^{14}$ with improvement of $B_{8}$ as shown in Fig. 10, the $B_{8}$ being a good indication of the degree of orientation alignment as mentioned earlier. As the figure is for $0.35 \mathrm{~mm}$ thick steel, the hysteresis loss, $W_{\mathrm{H}} 17 / 50$ (direct current hysteresis loss multiplied by 50) for a maximum magnetic flux density of 1.7 Tesla, decreases by 0.16 $\mathrm{W} / \mathrm{kg}$ with the improvement of $B_{8}$ from 1.82 to 1.92 Tesla. Better alignment of the grain orientation and improvement of $B_{8}$ properties are the first steps in reducing the total loss.

\section{Orientation and Tension Effect ${ }^{15,16)}$}

When a tensile stress is imposed on a sample with no surface coating, the $90^{\circ}$ domains decrease and the $180^{\circ}$ domains increase, causing the total loss to decrease. In the case of compression, the $90^{\circ}$ domains increase, and so does the total loss, but this varies widely depending on the degree of orientation alignment. In case of good orientation with $B_{8}=1.925$ Tesla as shown in Fig. 11, the total loss decreases greatly with tension and increases slightly with compression.

This phenomenon manifests itself distinctly for magnetostriction, too. As shown in Fig. 12, magnetostriction at $B=1.7$ Tesla becomes negative with tension, but, when the orientation alignment is as good as $B_{8}=1.94$ Tesla, the value remains to be very small, and although magnetostriction increases with compression this is smaller for better orientation alignment. Since magnetostriction is considered the principal cause of the transformer noise, lower magnetostriction and lower stress sensitivity of magnetostriction are desirable.

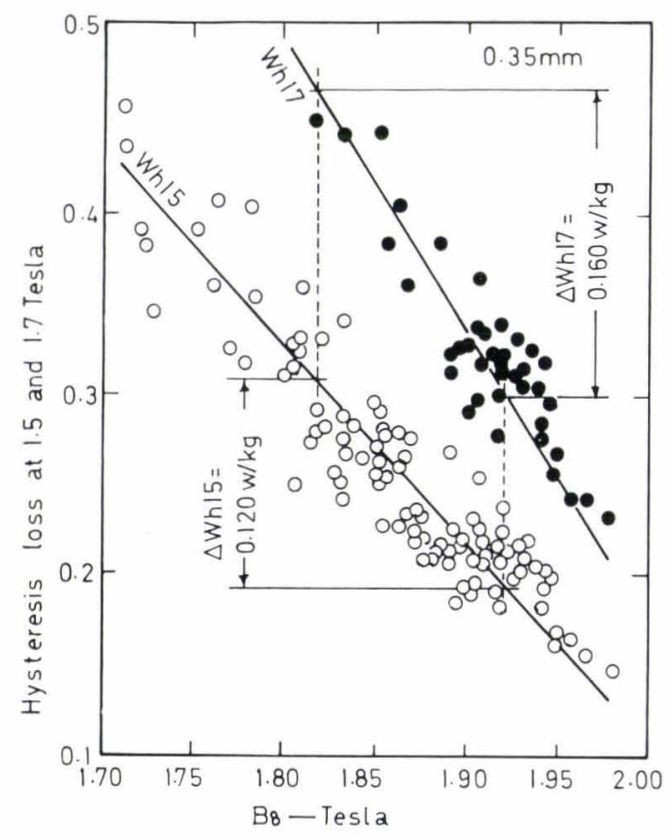

Fig. 10. Effects of $B_{8}$ value on hysteresis loss for grainoriented electrical steels
From this fact it is seen that provision of excellent orientation alignments is highly effective in improving magnetic properties under tension applied in the rolling direction. If such tension is available, therefore, drastic improvements in the magnetic properties can be expected.

Figure 13 shows the relation between total loss and d.c. hysteresis loss under tensile stress applied in the rolling direction. For reference, properties of (110) [001] single crystals (thickness $0.15 \mathrm{~mm}, B_{8}=2.03$ Tesla) are noted additionally. The total loss is decreased greatly in products of good orientation alignment. In products having $B_{8}=1.92$ Tesla the decrease of total loss with tension is mostly due to the decrease of eddy-current loss, whereas in those with $B_{8}=1.82$ Tesla the total loss decreases only slightly with tension and behaves about the same as hysteresis loss. In single crystals, on the other hand, the hysteresis loss varies slightly with tension and the total loss decreases very markedly due mostly to decrease of eddy-current loss.

Figure 14 shows the total loss at 1.0 Tesla $^{17}$ ) for

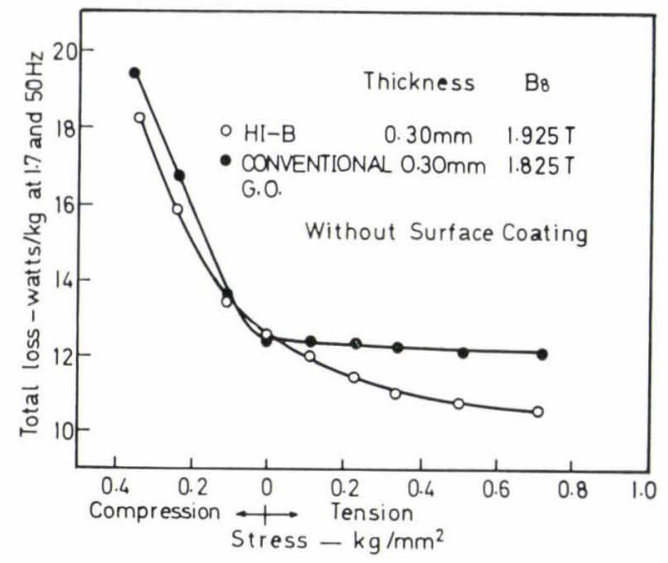

Fig. 11. Effect of stress applied along the rolling direction on total loss for HI-B and conventional grainoriented electrical steels

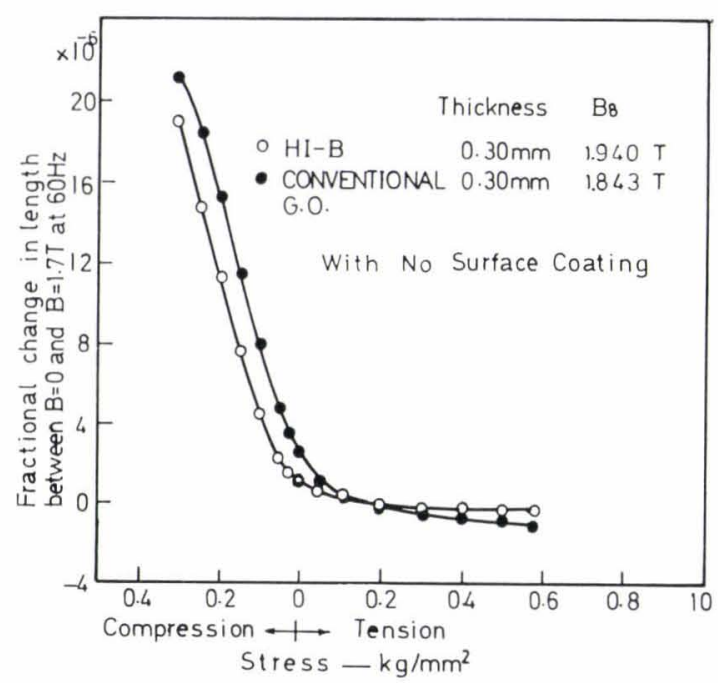

Fig. 12. Effect of stress applied along the rolling direction on magnetostriction for HI-B and conventional grain-oriented electrical steel 


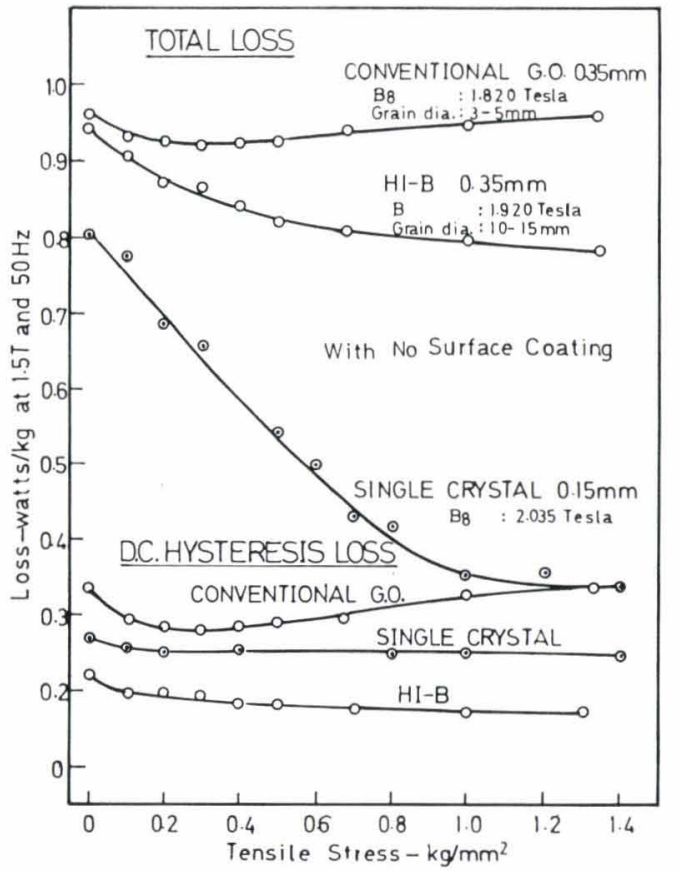

Fig. 13. Effect of degree of grain orientation alignment on the tensile stress dependence of total loss and d.c. hysteresis loss for grain-oriented electrical steel

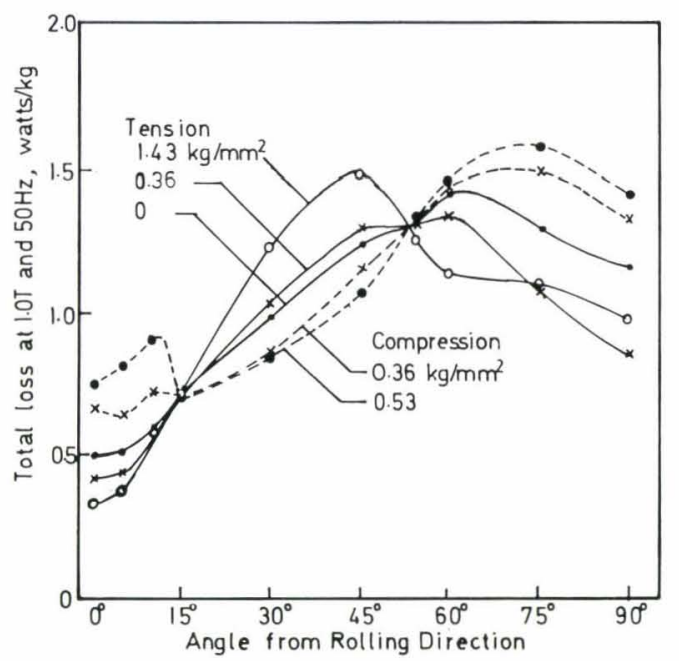

Fig. 14. Angluar dependence of applied stress on total loss for a $0.27 \mathrm{~mm}$ HI-B without surface coating $\left[B_{8}=\right.$ 1.95 Tesla] samples taken at various angles to the rolling direction and magnetized in the same sampling directions. The samples with $B_{8}=1.95$ Tesla, i.e., of the good orientation alignment, were without surface coating. In the samples prepared deviating about $10^{\circ}$ from the rolling direction, the total loss is decreased but only slightly by tension induced parallel to the direction of magnetization, and when the deviation exceeds $15^{\circ}$, the total loss increases with tension. This suggests that the tension effect cannot be expected to decrease the total loss except for products of good orientation alignment. In addition, the total loss does not change with an external force in the $55^{\circ}$ direction as this corresponds to the [111] axis direction.

Industrially, tension can be applied by the surface coating. ${ }^{16)}$ As the tension exerted on the sheet steel by the surface coating is isotropic for every direction in the plane of the sheet, it is different in character from the external tension applied in the rolling direction. Even so, thanks to the grain orientation of (110) [001], it develops an effect similar to the external tension in the rolling direction, and helps to improve the total loss and magnetostriction characteristics in the rolling direction.

As shown in Table 2, the external tension applied in the rolling direction improves both the total loss and magnetostrication in these directions. By the surface coating, however, even through the magnetic properties in the rolling direction are improved, both the total loss and the magnetostriction increase in the cross-rolling direction to deteriorate the overall quality. In the samples whose $B_{\mathrm{s}}$ is about 1.9 Tesla, the total loss and magnetostriction are improved by surface coating as effectively as by external tension.

Figure 15 shows how the total loss in various directions at 1.0 Tesla varies in the presence of surface coatings. It is seen that the total loss increases with increasing deviation from the rolling direction. Application of external tension lowers total loss in the cross-rolling direction, but, within $10^{\circ}$ from the rolling direction, the total loss has already been decreased due to coating, so it changes only slightly with external tension.

This tension effect by surface coating is more distinct in products of better orientation alignment and in products which receive greater tension from

Table 2. Effects of applied tensile stress and surface coating on total loss and magnetostriction $(\dot{o} l / l)$ of $\mathrm{HI}-\mathrm{B}$ in the rolling direction and cross-rolling direction $\left(B_{8}=1.92\right.$ Tesla $)$

\begin{tabular}{|c|c|c|c|c|c|c|}
\hline \multirow[b]{2}{*}{ (a) Rolling direction } & \multicolumn{5}{|c|}{ Applied stress $\left(\mathrm{kg} / \mathrm{mm}^{2}\right)$} & \multirow{2}{*}{$\begin{array}{l}\text { With } \\
\text { surface } \\
\text { coating }\end{array}$} \\
\hline & 0 & 0.11 & 0.23 & 0.33 & 0.47 & \\
\hline $\begin{array}{l}\text { Total loss }(\mathrm{W} / \mathrm{kg}) \text { at } 1.7 \text { Tesla and } \\
50 \mathrm{~Hz}\end{array}$ & 1.31 & 1.27 & 1.27 & 1.17 & 1.11 & 1.15 \\
\hline$\delta l / l \times 10^{-6}$ between 0 and 1.7 Tesla & +1.7 & +0.4 & -0.2 & -0.3 & -0.3 & -0.2 \\
\hline \multicolumn{7}{|l|}{ (b) Cross-rolling direction } \\
\hline $\begin{array}{l}\text { Total loss }(\mathrm{W} / \mathrm{kg}) \text { at } 10 \text { Tesla and } \\
50 \mathrm{~Hz}\end{array}$ & 1.25 & 1.08 & 0.92 & 0.86 & 0.87 & 1.80 \\
\hline$\delta l / l \times 10^{-6}$ between 0 and 1.0 Tesla & +8.9 & +7.8 & +5.3 & +2.2 & +0.7 & +10.7 \\
\hline
\end{tabular}




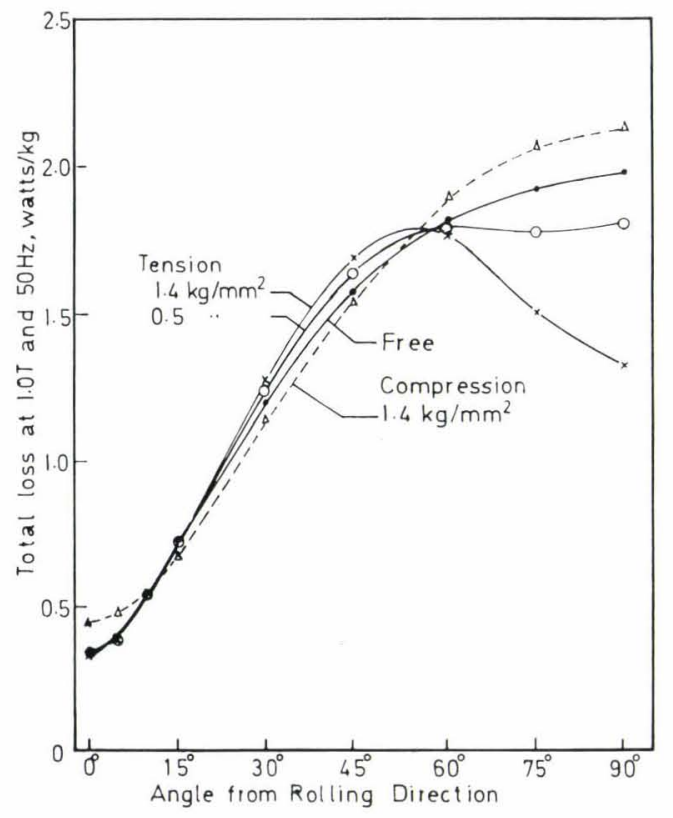

Fig. 15. Angular dependence of applied stress on total loss for a $0.27 \mathrm{~mm}$ HI-B with surface coating $\left[B_{8}=\right.$ 1.92 Tesla]

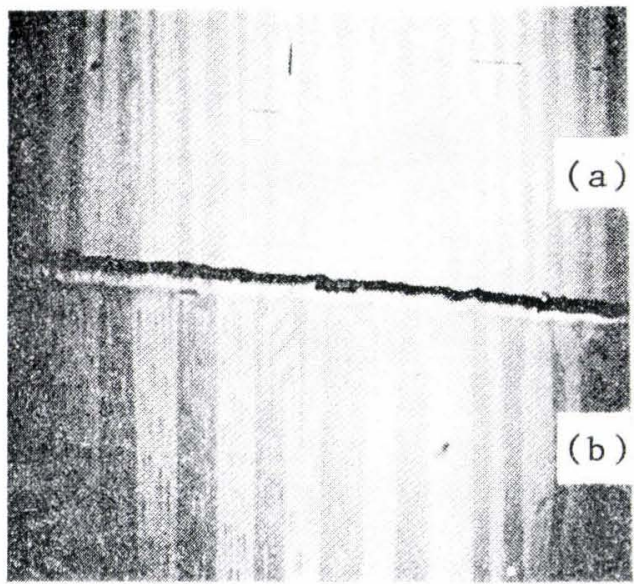

$3 \mathrm{~mm}$

(a) : with coating; (b): without coating

Photo 1. Change in domain pattern on removing coating for RG-H.

coating. For this reason, the effect can be further increased by applying an inorganic coating (S2 coating), which has a greater tensile effect, on top of the glass film. ${ }^{16)}$

The scanning electron microscope has made it possible to observe the magnetic domain in the presence of coating. ${ }^{18)}$ Photograph 1 shows variation of the magnetic domain on partial removal of the coating. ${ }^{19)}$ The line crossing the figure is the boundary between the section which retains the coating and the section from which the coating has been removed. It is shown that the tensile effect of the coating has eliminated the closure domain and narrowed the $180^{\circ}$ wall width.

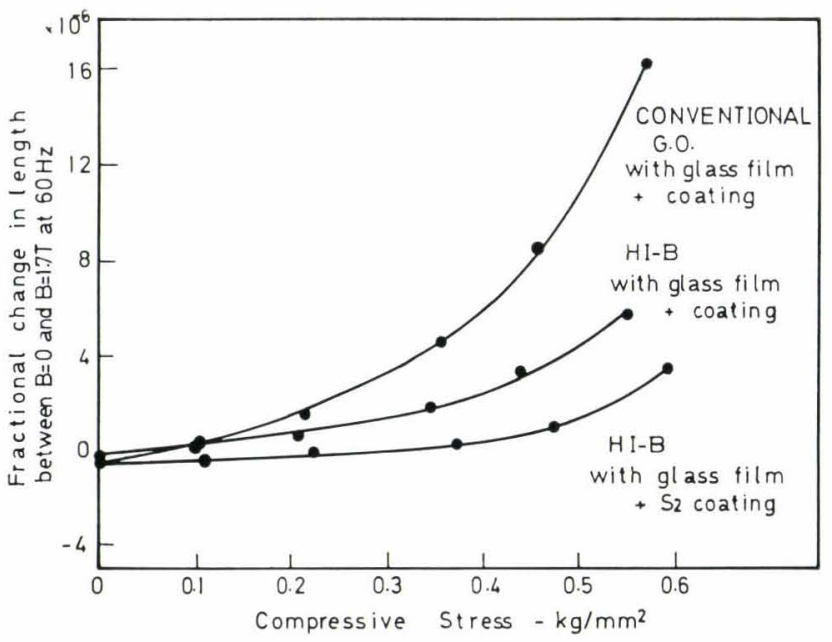

Fig. 16. Effect of the degree of grain orientation alignment and surface coating on the compressive stress dependence of magnetostriction for $0.3 \mathrm{~mm}$ grainoriented electrical steels

\section{Stress Sensitivity ${ }^{16,20}$}

Those properties of grain-oriented electrical steel which are important to transformers may be listed, in descending order of stress sensitivity, as magnetostrication, exciting power, and total loss; magnetostriction being the most sensitive. The elastic surface tension by surface coating to reduce magnetostriction is in itself not very necessary, yet if the stresses occurring in the actual assembly and fabrication of transformer cores are considered, it is necessary to lower the stress sensitivity.

Of the stresses working on a sheet, which may be classified broadly into tensile stress and compressive stress, the compressive stress in the rolling direction of the steel increases magnetostriction. In practice, one-side compressive stress due to curvature is a problem. Compression from the sheet surface presents no problem if it is uniform, yet in practice it is likely to become non-uniform, inducing longitudinal compressive stress and increasing magnetostriction.

Figure 16 shows the changes of magnetostriction in conventional and HI-B electrical steel sheets under compressive forces. It is seen that products having a surface coating of great elastic surface tension are exceedingly low in stress sensitivity.

Thus it has been seen that, while in the development of grain-oriented electrical steels attainment of high permeability and $B_{8}$ was mainly achieved by increasing the degree of orientation alignment, in the development of commercial products with excellent overall magnetic properties the utilization of the tensile effects of surface coating contributed greatly.

3. Performance of Grain-oriented Electrical Steel with High Permeability in Transformers

At present, the grain-oriented electrical steel HI-B is not only well used in Japan but it is being exported to and used in various countries of the world. Figure 17 is drawn on the basis of reports from the manufacturers of electrical equipment using the steel. First, 


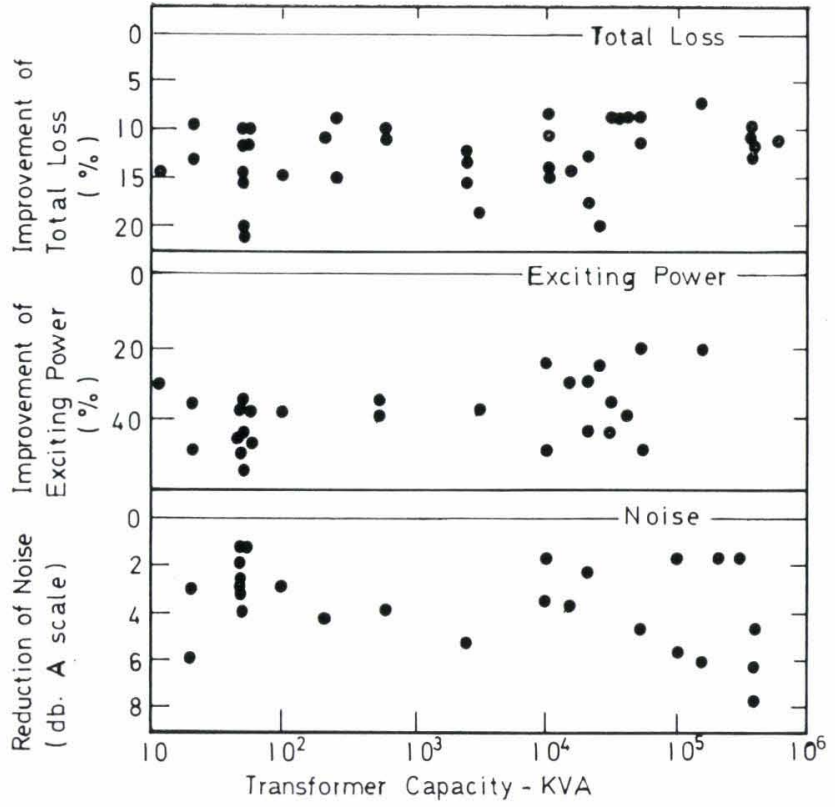

Fig. 17. Comparison of characteristics of actual transformers made on the same design but using HI-B or conventional materials

as for the very important total loss, improvements of about $15 \%$ were obtained, generally in proportion to the improvement gained in the material properties, in all transformers from super-large transformers of 600 MVA class to wound core compact transformers of the order of $10 \mathrm{kVA}$. With regard to other properties of concern, the improvement has been impressive: the exciting power has been reduced to about a half, and the noise level is lowered as much as 8 phons, 4 to 5 phons on the average. ${ }^{20)}$

A recent announcement made by a Japanese manufacturer of electrical equipment ${ }^{21}$ states that in the manufacture of more than ten 3-phase transformers of 500 to 1000 MVA using $0.35 \mathrm{~mm}$ HI-B sheets, it was experienced that the total loss decreased by $10 \%$, exciting power by about $40 \%$, and transformer noise by 4 to 7 phons, as compared with transformers using conventional grain-oriented electrical steel sheets.

\section{Recent Progress and Future Development of Grain-ori- ented Electrical Steel with High Permeability}

The improvement of total loss has been attained $^{22,23)}$ through improved $B_{8}$ properties, the tensile effect of coatings, decreased sheet thickness, improved cleanliness, increased silicon content, refined gain size, etc.

Figure 18, an illustration of the relation between total loss and sheet thickness, reveals that the total loss decreases with decreasing sheet thickness, and that it is more so the higher the $B_{8}$, i.e., the better the orientation alignment.

Figure 19 shows the influence of steel cleanliness on total loss: even though $\mathrm{MnS}$ or $\mathrm{AlN}$ is removed during box annealing, such impurities as $\mathrm{SiO}_{2}$ or $\mathrm{Al}_{2} \mathrm{O}_{3}$ remain and exert unfavorable influence on the total loss. In the figure, A, B and C denote sheets made by different melting methods; A which has a decreased

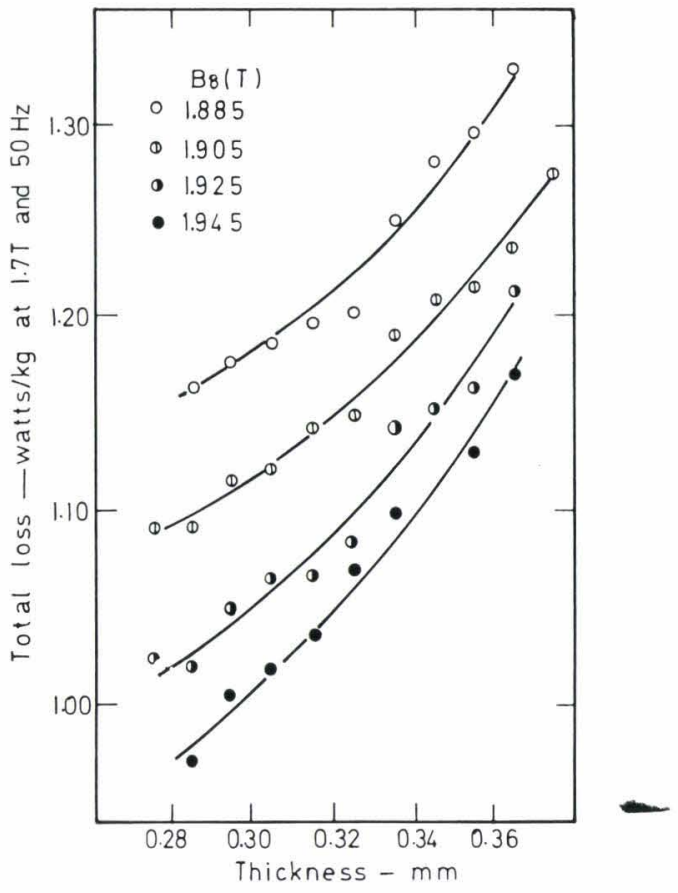

Fig. 18. Effect of thickness on total loss at 1.7 Tesla

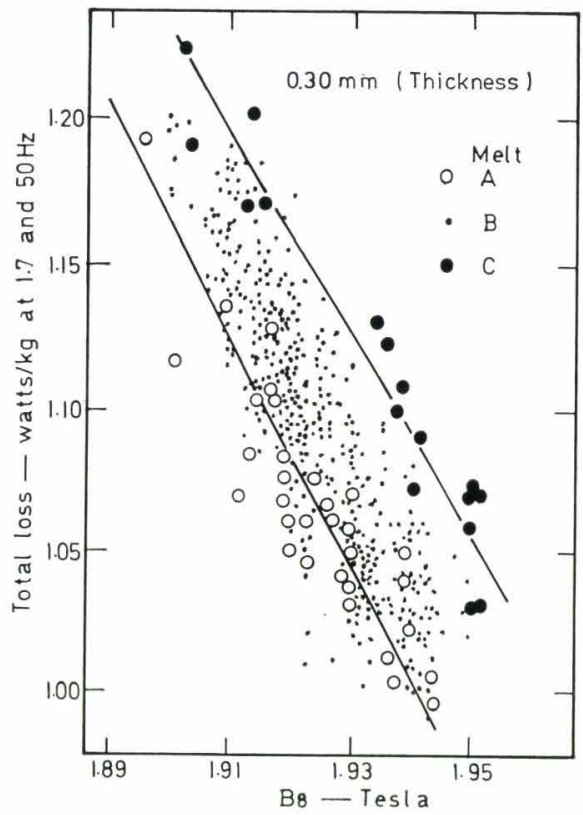

Fig. 19. Effect of melting method on total loss at 1.7 Tesla

content of micro-inclusion shows excellent total loss performance. Figure 20, an illustration of the relation between total loss and $B_{8}$, discloses that grain size influences the total loss also, and Fig. 21 shows the influence of silicon content on total loss.

As a result of efforts made toward these targets, some data of total loss $W_{17 / 50}$ (at 1.7 Tesla and 50 $\mathrm{Hz}$ ) are represented in Table 3 as typical values for experimental products.

As has been stated, tension applied in the rolling direction of sheets having a good orientation alignment decreases their total loss markedly. Moreover, a great tension is produced by scratching the sheet surface $;^{17}$ while a strong compression is induced in 


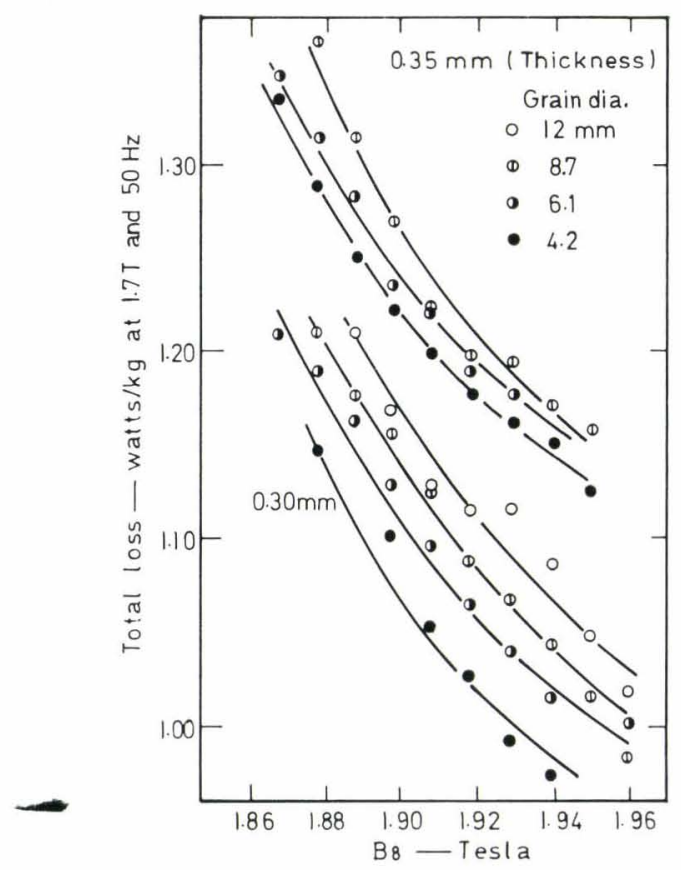

Fig. 20. Effect of permeability on total loss at 1.7 Tesla

Table 3. Typical total loss values in the experimental products of HI-B due to new technical development

\begin{tabular}{cc} 
Sheet thickness & Total loss at 1.7 Tesla, $50 \mathrm{~Hz}$ \\
\hline $0.35 \mathrm{~mm}$ & $1.13 \mathrm{~W} / \mathrm{kg}$ \\
$0.30 \mathrm{~mm}$ & $0.98 \mathrm{~W} / \mathrm{kg}$ \\
$0.28 \mathrm{~mm}$ & $0.95 \mathrm{~W} / \mathrm{kg}$
\end{tabular}

the vicinity of scratches, a strong tension prevails at distances, so that scratches made along the cross-rolling direction are the most effective in reducing the total loss. Figure 22 represents the results of scratches made at a $10 \mathrm{~mm}$ interval along the cross-rolling direction on the surface of three types of grain-oriented sheets. Even in the absence of scratches, the total loss of the sheet with a $B_{8}$ of 1.98 Tesla sharply decreases on imposition of tension. When scratched it becomes less than $0.8 \mathrm{~W} / \mathrm{kg}$, and with tension imposed further, it becomes as small as $0.58 \mathrm{~W} / \mathrm{kg}$, a value which is about one half the total loss observed in existing grain-oriented electrical steels with high permeability. It is likely that, provided the orientation alignment is improved to a certain degree, then as the tensile effect is strengthened, the domain width narrows, the anomalous eddy-current loss decreases, and extremely low total loss values become obtainable. The fact that such total loss values have been actually obtained though on a laboratory basis suggests there still is a great room for future development.

\section{Special Electrical Steel}

As special grades of electrical steel, there are the thin-gauge electrical steel which is used for high frequency services, and the cube textured electrical steel which has the (100) planes aligned parallel to the rolling surface.

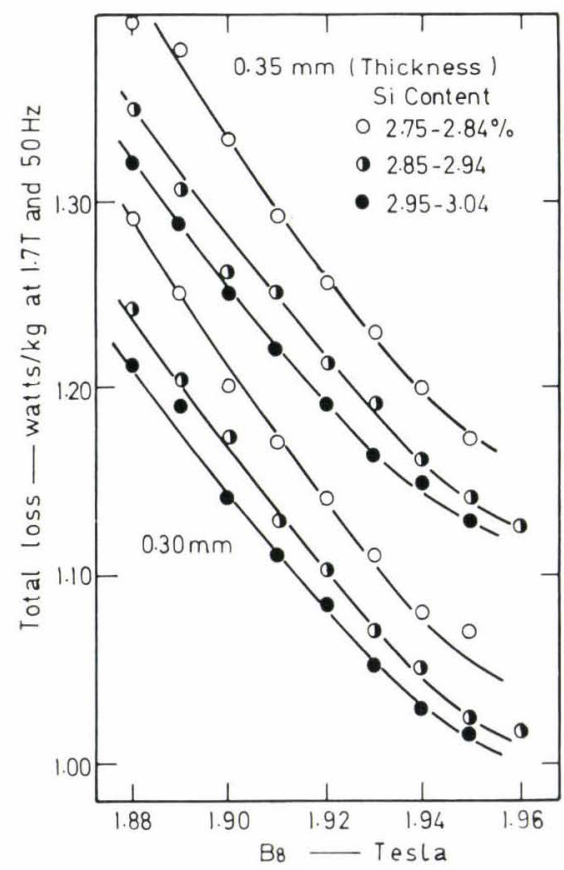

Fig. 21. Effect of [Si] content on total loss at 1.7 Tesla

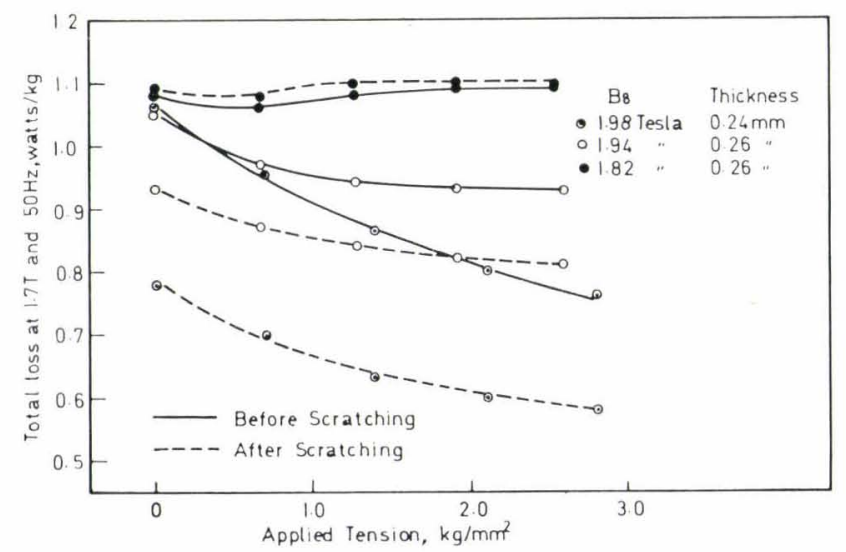

Surface roughness: about $10 \mu$ inch r.m.s.

Fig. 22. Effect of scratching on total loss for grain-oriented electrical steels. The surface was chemically polished and then scratched in the cross-rolling direction with an interval of $10 \mathrm{~mm}$ on the upper side.

\section{Thin-gauge Electrical Steel}

Thin-gauge electrical steels are manufactured out of grain-oriented electrical steel sheets by pickling, cold reducing, annealing and providing on the surface an insulation coating. ${ }^{24}$. They are produced mostly in thicknesses of $0.1,0.05$ and $0.025 \mathrm{~mm}$, but in Japan, it is being produced only in thicknesses of 0.1 and $0.05 \mathrm{~mm}$ and in very small quantities.

\section{Cube Textured Electrical Steel}

This steel attracted the attention of researchers throughout the world for some time after it was announced ${ }^{25)}$ by F. Assmus and others in 1957. The method is one in which the difference in surface energy of the crystal plane is utilized: through high-tem- 
perature annealing in a clean no surface-oxidizing condition the (100) planes are aligned parallel to the sheet surface on secondary recrystallization. It was called the doubly oriented electrical steel because the crossrolling direction can take the [010], also an axis of easiest magnetization, if [001] is aligned in the rolling direction. The cube textured electrical steel developed by Armco Steel Corporation had (100) planes parallel to the sheet surface, but the [001] directions were not aligned to the rolling direction. ${ }^{26}$ Produced in small quantities, they were used for the cores of aircraft generators and other applications, but their production was terminated in 1973. The Vaccumshmelze Company also seems to have produced them in very small quantities. It was found that in addition to the high manufacturing cost due to the need for special box annealing, they had the inherent shortcoming of developing too much magnetostrication, the main cause of transformer noise, to be used in transformer cores, the main application for grain-oriented electrical steel. It is as if the cube textured electrical steel succeeded technically but failed industrially. At present there is no research under way on this steel.

\section{Conclusion}

The recent progress of electrical steel in Japan has been remarkable both in quality and quantity. It is found especially in the grain-oriented electrical steel with high permeability, an innovative product, which was developed ahead of the rest of the world and won high recognition. This product is expected to see further improvements in the future.

\section{REFERENCES}

1) R. A. Hadfield: U.S. Patent (U.S.P.) 745,829, (1903).

2) N. P. Goss: U.S.P. 1,965,559, (1934).

3) V. W. Carpenter and J. M. Jackson: U.S.P. 2,287,467, (1942).

4) V.W. Carpenter: U.S.P. 2,385,332, (1945).
5) M. F. Littmann and J. E. Heck: U.S.P. 2,559,340, (1952).

6) S. Taguchi and A. Sakakura: U.S.P. 3,159,511, (1964).

7) S. Taguchi, A. Sakakura and H. Takashima: U.S.P. $3,287,183$, (1966).

8) A. Sakakura, S. Taguchi, T. Wada, K. Ueno, T. Yamamoto and N. Urushiyama: U.S.P. 3,636,579, (1972).

9) T. Imanaka, T. Kan, Y. Obata and T. Sato: W. Germany Patent, OLS 2,351,141, (1974).

10) S. Taguchi and A. Sakakura: Acta Met, 14 (1966), 405.

11) A. Sakakura: J. Appl. Phys., 40 (1969), 1534.

12) F. Matsumoto, K. Kuroki and A. Sakakura: Amer. Inst. Phys. Conference Proc., Magnetism and Magnetic Materials, 24 (1974), 716.

13) I. Goto, I. Matoba, T. Imanaka, T. Gotoh, and T. Kan: European Phys. Soc. Conference Proc., Soft Magnetic Materials II, Cardiff, (1975).

14) S. Taguchi and A. Sakakura: J. Appl. Phys., 40 (1969), 1539.

15) T. Yamamoto and T. Nozawa: J. Appl. Phys., 41 (1970), 2981.

16) T. Yamamoto, S. Taguchi, A. Sakakura and T. Nozawa: IEEE Trans, on Magnetics, 8 (1972), 677.

17) T. Yamamoto and S. Taguchi: European Phys. Soc. Conference Proc.,Soft Magnetic Materials II, Cardiff, (1975).

18) T. Yamamoto and K. Tsuno: Amer. Inst. Phys. Conference Proc., Magnetism and Magnetic Materials, 29 (1975), 572.

19) I. Irie and B. Fukuda: Amer. Inst. Phys. Conference Proc., Magnetism and Magnetic Materials, 29 (1975), 574.

$20)$ S. Taguchi, T. Yamamoto and A. Sakakura: IEEE Trans. on Magnetics, 10 (1974), 123.

21) S. Wada, S. Shimizu and S. Taguchi: European Phys. Soc. Conference Proc. Soft Magnetic Materials II, Cardiff, (1975).

22) A. Sakakura, T. Wada, F. Matsumoto, K. Ueno, K. Takashima and M. Kawashima: Amer. Inst. Phys. Conference Proc., Magnetism and Magnetic Materials, 24 (1974), 714.

23) S. Taguchi, A. Sakakura, F. Matsumoto, K. Takashima and K. Kuroki: J. Magnetism and Magnetic Materials, 2 (1976), 121.

24) M. F. Littmann: U.S.P. 2,473,156 (1949).

25) F. Assmuss, K. Detert and G. Ibe: Z. Metallk., 48 (1957). 344.

26) D. M. Kohler: J. Appl. Phys., 31 (1960), 408. 